\title{
HIGIENIZAÇÃO DAS MÃOS COMO MEDIDA PARA SEGURANÇA DO PACIENTE NA
}

\author{
ATENÇÃO BÁSICA
}

\author{
Priscila da Silva Matter ${ }^{1}$ \\ Carine Feldhaus ${ }^{2}$ \\ Thays Cristina Berwig Rutke ${ }^{3}$ \\ Marinez Koller Petenon 4 \\ Adriane Cristina Bernat Kolankiewicz ${ }^{5}$ \\ Marli Maria Loro ${ }^{6}$ \\ Recebido em: 25 abr. 2018 \\ Aceito em: 19 mar. 2019
}

RESUMO: OBJETIVO: Avaliar e comparar o conhecimento sobre higienização das mãos de médicos e equipe de enfermagem, atuantes na atenção básica. MÉTODO: Estudo transversal, de caráter quantitativo. Realizado com profissionais de saúde que atuam na atenção básica. Coleta de dados com o instrumento Teste de Conhecimento a Respeito da Higienização das Mãos para Profissionais da Saúde. RESULTADOS: As categorias profissionais conhecem a principal via de transmissão cruzada de microrganismos. Sobre a técnica de higienização das mãos, a maioria, identifica que a preparação alcoólica deve cobrir todas as superfícies das mãos, as mesmas devem estar secas antes do uso e não se deve utilizar papel toalha após. Entre o conhecimento das categorias profissionais não houve diferença estatística. CONCLUSÃO: Resultados demonstram conhecimento, mas lacunas são identificadas. Necessárias ações educativas sobre a temática e novos estudos devem ser realizados com metodologias distintas.

Palavras-chave: Segurança do Paciente. Enfermagem. Conhecimento. Higiene das Mãos. Atenção Primária à Saúde.

\section{HYGIENIZATION OF HANDS AS A MEASURE FOR PATIENT SAFETY IN BASIC}

\section{ATTENTION}

ABSTRACT: OBJECTIVE: To evaluate and compare the knowledge about the hygiene of the hands of physicians and nursing staff, who work in basic care. METHOD: Cross-sectional, quantitative study. Performed with health professionals who work in basic care. Data collection with the Knowledge Testing Tool on Hand Hygiene for Health Professionals. RESULTS: The professional categories know the main way of cross-transmission of microorganisms. On the hand hygiene technique,

\footnotetext{
${ }^{1}$ Enfermeira. Residente no programa de Residência Multiprofissional em Saúde da Família da Universidade Regional do Noroeste do Estado do Rio Grande do Sul (UNIJUÍ). E-mail: prymatter@hotmail.com.

${ }^{2}$ Enfermeira. Residente em Gerenciamento de Enfermagem em Clinica médica e cirúrgica, Universidade Estadual do Oeste do Paraná (UNIOESTE).E-mail: carine0212@hotmail.com.

${ }^{3}$ Enfermeira. Pós-graduanda Latu Sensu em Enfermagem Obstétrica pela Universidade Regional do Noroeste do Estado do Rio Grande do Sul (UNIJUí). E-mail: thaysrutke@hotmail.com.

4 Enfermeira. Mestre em Educação. Docente do Curso de Enfermagem da UNIJUÍ.E-mail: marinez.koller@unijui.edu.br.

${ }^{5}$ Enfermeira. Doutora em Ciências. Docente do Curso de Enfermagem e do Programa de Mestrado Atenção Integral à Saúde da UNIJUÍ. E-mail: adri.saudecoletiva@gmail.com.

6 Enfermeira. Doutora em Ciências. Docente do Curso de Enfermagem da UNIJUÍ. E-mail: marlil@unijui.edu.br.
} 
most identify that alcoholic preparation should cover all surfaces of hands, they should be dry before use and should not be used paper towels after. Among the knowledge of the professional categories there was no statistical difference. CONCLUSION: Results demonstrate knowledge, but gaps are identified. Necessary educational actions on the subject and new studies must be carried out with different methodologies.

Keywords: Patient Safety. Nursing. Knowledge. Hand Hygiene. Primary Health Care.

\section{INTRODUÇÃO}

$\mathrm{Na}$ contemporaneidade a segurança do paciente e a qualidade do cuidado são discussões em evidência no âmbito dos serviços de saúde. Segundo a Organização Mundial da Saúde (OMS), garantir a segurança do paciente é reduzir a um mínimo aceitável o risco de dano desnecessário associado à assistência (BRASIL, 2014).

Em reconhecimento à importância e magnitude deste tema a OMS, criou no ano de 2004, a Aliança Mundial para a Segurança do Paciente. Em 2005, esta aliança estabeleceu seis metas internacionais de segurança do paciente, dentre elas, a redução de riscos de infecções aliadas ao cuidado em saúde, com ênfase na lavagem das mãos, como medida preventiva primária (BRASIL, 2014).

No Brasil, a OMS trabalha este tema em parceria com a Agência Nacional de Vigilância Sanitária (ANVISA) desde 2007 e desenvolve ações de promoção e prevenção de infecções em serviços de saúde, dentre elas, os cinco momentos para a Higienização das Mãos (HM), técnica correta e produtos utilizados (BRASIL, 2009).

O termo higienizar corresponde à higienização simples, com água e sabonete e higienização antisséptica, com sabonete antisséptico degermante por 40 a 60 segundos, ou a fricção antisséptica, com preparação alcoólica por 20 a 30 segundos (BRASIL, 2013). Ainda, para facilitar a compreensão sobre as situações em que há riscos de transmissão de microrganismos pelas mãos, foram estabelecidos os cinco momentos para HM, definidos como: antes de tocar no paciente, antes de realizar procedimento limpo/asséptico, após risco de exposição a fluídos corporais, após tocar o paciente e após tocar superfícies próximas ao paciente (BRASIL, 2013).

Nos serviços de saúde os profissionais fazem de suas mãos a principal ferramenta de trabalho, assim a segurança dos pacientes, depende diretamente da sua higienização adequada e frequente (SILVA et al., 2013). Embora seja uma medida simples e eficaz para prevenir infecções, erros associados ao cuidado de saúde que ocorrem por meio das mãos representam cerca de 50\% das infecções hospitalares (LIMA, 2014). Na atenção básica a HM é uma atitude de segurança, com uma grande capacidade de prevenir infecções cruzadas, bastante esquecida pelos profissionais, sendo assim, faz-se necessário a adoção de medidas de intervenção (SOUZA et al., 2016).

Estima-se que mais de 1,4 milhão de pessoas em todo o mundo são acometidas diariamente por Infecções Relacionadas à Assistência à Saúde (IRAS) que podem ser 
evitadas (SOUZA et al., 2015). No Brasil, calcula-se que 3\% a $15 \%$ das pessoas hospitalizadas desenvolvem alguma IRAS, o que indica um problema para a segurança do paciente, pois implicam em prolongada permanência hospitalar, elevado encargo financeiro para o sistema de saúde, pacientes e familiares, bem como aumento da morbidade e mortalidade (ANVISA, 2008).

Desta forma, o conhecimento sobre a HM bem como a adesão a esta prática, tornase indispensável entre os profissionais de saúde, em qualquer nível de atenção, tendo em vista a redução de agravos causados por infecções. Destaca-se que no Brasil a maioria dos estudos referentes a este tema são realizados em hospitais. Assim, identifica-se uma lacuna no conhecimento e há a necessidade de investigações acerca da temática em outros locais que realizam assistência à saúde.

A partir do exposto, com base nos pressupostos da segurança do paciente, nas recomendações da OMS sobre a HM e, consequências da baixa adesão a esta prática, este trabalho tem como questão norteadora: Qual é o conhecimento dos profissionais de saúde que atuam na atenção básica a respeito da higienização das mãos? Contemplada no objetivo geral avaliar e comparar o conhecimento sobre higienização das mãos de médicos e equipe de enfermagem, atuantes na atenção básica.

\section{MÉTODO}

Estudo transversal, de caráter quantitativo, desenvolvido em 20 unidades da atenção básica de um município do Estado do Rio Grande do Sul (RS) - Brasil. Destas 15 são Estratégias de Saúde da Família (ESF) e cinco Unidades Básicas de Saúde (UBS).

Os critérios de inclusão foram: ser enfermeiro, técnico de enfermagem, auxiliar de enfermagem ou médico, ter 18 anos de idade ou mais e trabalhar há mais de 30 dias naquela unidade. Foram excluídos os profissionais que se encontravam em licença saúde, afastados das atividades laborais durante o período da coleta ou que não deram retorno após três tentativas de contato.

O período da coleta de dados foi de julho a outubro de 2016. No período de coleta 106 profissionais faziam parte da população estimada, 73 atuavam em ESF e 33 em UBS.

Após aplicar os critérios de inclusão e exclusão, foram excluídos três profissionais por estarem em licença saúde, dois após três tentativas de contato sem sucesso e 17 não aceitaram participar da pesquisa. Desta forma, a população de estudo foi de 84 trabalhadores.

A coleta de dados foi realizada por uma acadêmica de enfermagem, previamente capacitada. Utilizou-se como instrumento de pesquisa o Teste de Conhecimento a Respeito da Higienização das Mãos para Profissionais da Saúde, validado pela OMS, inseridos na estratégia multimodal para promover boas práticas de higiene das mãos ${ }^{(8)}$.

Este é um questionário autoaplicável, composto por 26 questões de múltipla 
escolha, com perguntas que avaliam o conhecimento técnico e científico sobre os aspectos da higienização das mãos durante a assistência à saúde. Destas, 13 são questões de caracterização sociodemográfico e laboral e 13 questões de múltipla escolha, verdadeiro ou falso, sim ou não, para avaliar a conhecimento dos profissionais em relação à higienização das mãos.

A abordagem dos profissionais ocorreu nas unidades de saúde, após a apresentação dos objetivos da pesquisa e, quando do aceite para integrar o estudo, 0 mesmo foi convidado a assinar o Termo de Consentimento Livre e Esclarecido, em duas vias, sendo que, uma permaneceu com o entrevistado e outra com a pesquisadora. Após esclarecer a forma de preenchimento, o questionário foi deixado em um envelope com o profissional e recolhido em outro momento, estabelecido previamente.

Após a coleta, na análise descritiva dos dados utilizou-se o programa PASW Statistics ${ }^{\circledR}$ (Predictive Analytics Software, da SPSS Inc., Chicago - USA) 18.0 for windows. As variáveis estão descritas em número e percentual e para verificar a existência de associação entre as variáveis estudadas utilizou-se o teste Qui-quadrado de Pearson, consideradas estatisticamente significantes se $p<0,05$.

Pesquisa aprovada pelo Comitê de Ética em Pesquisa (CEP) da Universidade Regional do Noroeste do Estado do Rio Grande do Sul (UNIJUI), sob CAAE 47106715.2.0000.

\section{RESULTADOS}

Participaram do estudo 84 profissionais, o que representa uma taxa de resposta de $79 \%$, sendo que 66(78,5\%) atuavam em ESF e 18(21,4\%) em UBS. Em relação à classe profissional 58(69\%) corresponde à equipe de enfermagem, destes $21(25 \%)$ eram enfermeiros, 24(28,6\%) técnicos de enfermagem e 13(15,5\%) auxiliares de enfermagem. Em relação ao sexo dos participantes da equipe de enfermagem 54(93,1\%) eram do sexo feminino e 40(68,9\%) estão na faixa etária de 28 a 47 anos de idade. A classe médica totalizou 26(31\%) dos entrevistados, com prevalência de $18(69,2 \%)$ do sexo feminino e $13(50 \%)$ com idade até 37 anos. Referente ao tempo de atuação, 46(54,8\%) participantes atuavam há mais de cinco anos na instituição e 73(86,9\%) cumpriam 40 horas semanais.

No que tange a receber treinamento sobre $\mathrm{HM}, 35(60,4 \%)$ dos profissionais de enfermagem e 16(61,5\%) da classe médica responderam, positivamente. Sobre ter alguma preparação alcoólica disponível para HM na instituição, 57(98,2\%) profissionais da enfermagem e $25(96,2 \%)$ da classe médica reconheceram que existe. Em relação à principal rota de transmissão cruzada de microrganismos entre pacientes nos serviços de saúde, 50(86,2\%) profissionais de enfermagem e $24(92,3 \%)$ dos médicos afirmam ser as mãos do profissional quando não estão higienizadas.

No que se refere ao conhecimento do tempo mínimo necessário para preparação alcoólica destruir os microrganismos nas mãos, os participantes do estudo que compõem 
a equipe de enfermagem $7(12 \%)$ responderam 3 segundos, 16(27,5\%) 10 segundos, $21(36,2 \%) 20$ segundos e $14(24,1 \%) 60$ segundos. Já os profissionais médicos, $5(19,2 \%)$ afirmaram ser 3 segundos, 3(11,5\%) 10 segundos, 8(30,8\%) 20 segundos e 10(38,5\%) 60 segundos, como é evidenciado no gráfico 1. Quando relacionado o conhecimento entre categorias profissionais com o uso do teste Qui-quadrado de Pearson mostrou que não ocorreu significância estatística com valor de $\mathrm{p}=0,248$.

Gráfico 1: Conhecimento de profissionais da classe médica e de enfermagem da atenção básica, referente ao tempo mínimo para higienização das mãos. Rio Grande do Sul, Brasil, 2016.

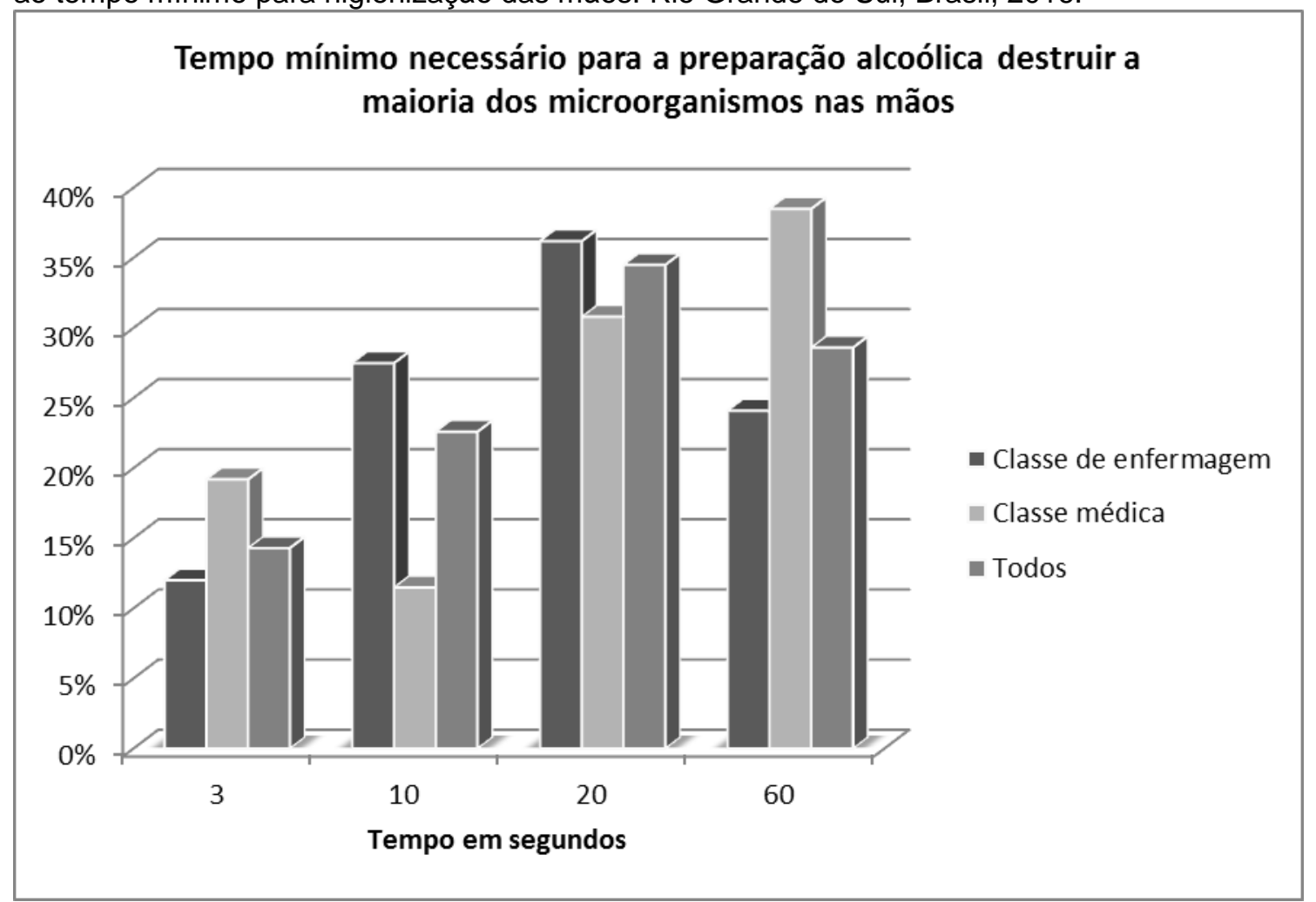

Fonte: Dados dos autores.

A tabela 1 revela dados sobre o conhecimento da técnica de $\mathrm{HM}$ e itens evitáveis. $\mathrm{Na}$ análise descritiva por questão prevaleceu a afirmação de que a preparação alcoólica deve cobrir todas as superfícies das mãos, com 56(96,5\%) da enfermagem e $26(100 \%)$ dos médicos, $84 \%$ com percentuais iguais em ambas as classes profissionais, afirmaram que as mãos devem estar secas antes do uso, destaca-se que $14(24,1 \%)$ da enfermagem entende que deve-se secar as mãos após fricção com preparação alcoólica. Ainda, ambas as categorias afirmaram que adornos devem ser evitados. Quando relacionado o conhecimento entre profissionais o teste não evidenciou significância estatística. 
Tabela 1. Distribuição de respostas referente ao conhecimento da técnica de higienização das mãos com preparação alcoólica e itens a serem evitados pela possibilidade de colonização, segundo grupos profissionais atuantes na atenção básica de um município do noroeste do Estado do Rio Grande do Sul, Brasil. 2016.

\begin{tabular}{|c|c|c|c|c|}
\hline Variáveis & $\begin{array}{l}\text { Classe de } \\
\text { enfermagem } \\
\text { Sim } \\
N(\%)\end{array}$ & $\begin{array}{l}\text { Classe } \\
\text { médica } \\
\text { Sim } \\
N(\%)\end{array}$ & $\begin{array}{l}\text { Total } \\
\text { Sim } \\
\text { N (\%) }\end{array}$ & $\mathbf{p}^{*}$ \\
\hline \multicolumn{5}{|l|}{$\begin{array}{l}\text { Técnica de higienização das } \\
\text { mãos com preparação alcoólica }\end{array}$} \\
\hline $\begin{array}{l}\text { Deve cobrir todas as superfícies } \\
\text { de ambas as mãos }\end{array}$ & $56(96,5 \%)$ & $26(100 \%)$ & $82(97,6 \%)$ & 0,338 \\
\hline Mãos secas antes do uso & $49(84,4 \%)$ & $22(84,6 \%)$ & $71(84,5 \%)$ & 0,988 \\
\hline Secar as mãos após fricção & $14(24,1 \%)$ & $5(19,2 \%)$ & $19(22,6 \%)$ & 0,619 \\
\hline \multicolumn{5}{|l|}{$\begin{array}{l}\text { Itens evitáveis pela } \\
\text { possibilidade de colonização } \\
\text { das mãos }\end{array}$} \\
\hline Jóias & $53(91,3 \%)$ & $26(100 \%)$ & $79(94 \%)$ & 0,123 \\
\hline Unhas postiças & $55(94,8 \%)$ & $26(100 \%)$ & $81(96,4 \%)$ & 0,238 \\
\hline Creme para as mãos & $24(41,3 \%)$ & $9(34,6 \%)$ & $33(39,3 \%)$ & 0,557 \\
\hline
\end{tabular}

$\mathrm{Na}$ análise descritiva da tabela 2, que representa dados sobre os meios de contaminação das mãos e momentos da higienização, observa-se unanimidade ao afirmarem que o contato com a maçaneta da porta constitui uma das formas de contaminação das mãos, ainda $66(78,6 \%)$ do total afirmaram sobre a pele intacta de outro paciente, $57(67,9 \%)$ a pele intacta do próprio paciente e $62(73,8 \%)$ o prontuário do paciente.

Evidencia-se também, que em relação às ações de HM que evitam transmissão cruzada de microrganismos ao paciente $83(98,8 \%)$ do total de participantes afirmam antes de contato com o paciente, $81(96,4 \%)$ após contato com fluídos corporais e $51(87,9 \%)$ da enfermagem e 22(84,6\%) dos médicos após exposição a superfícies próximas ao paciente. Não apresentou significância estatística entre o conhecimento das categorias profissionais. 
Tabela 2. Distribuição das respostas quanto às superfícies contaminantes das mãos e momentos da higienização, por grupos profissionais atuantes na atenção básica de um município do Noroeste do Estado do Rio Grande do Sul, Brasil, 2016.

\begin{tabular}{|c|c|c|c|c|}
\hline Variáveis & $\begin{array}{l}\text { Classe de } \\
\text { enfermagem } \\
\text { Sim } \\
\text { N (\%) }\end{array}$ & $\begin{array}{l}\text { Classe médica } \\
\text { Sim } \\
\text { N }(\%)\end{array}$ & $\begin{array}{l}\text { Total } \\
\text { Sim } \\
\text { N (\%) }\end{array}$ & $\mathbf{p}^{*}$ \\
\hline \multicolumn{5}{|l|}{$\begin{array}{l}\text { Superfícies que podem contaminar as } \\
\text { mãos e ocorrer transmissão de } \\
\text { microrganismos aos pacientes }\end{array}$} \\
\hline Maçaneta da porta & $55(94,8 \%)$ & $25(96,2 \%)$ & $80(95,2 \%)$ & 0,792 \\
\hline Pele intacta de outro paciente & $45(77,5 \%)$ & $21(80,8 \%)$ & $66(78,6 \%)$ & 0,742 \\
\hline Pele intacta do próprio paciente & $40(68,9 \%)$ & $17(65,4 \%)$ & $57(67,9 \%)$ & 0,745 \\
\hline Prontuário do paciente & $43(74,1 \%)$ & $19(73,1 \%)$ & $62(73,8 \%)$ & 0,919 \\
\hline $\begin{array}{lcr}\text { Higiene das mãos que evita } \\
\text { transmissão } & \text { cruzada } & \text { de } \\
\text { microrganismos ao paciente } & \end{array}$ & & & & \\
\hline Antes de contato com o paciente & $57(98,2 \%)$ & $26(100 \%)$ & $83(98,8 \%)$ & 0,501 \\
\hline após contato com fluídos corporais & $55(94,8 \%)$ & $26(100 \%)$ & $81(96,4 \%)$ & 0,238 \\
\hline $\begin{array}{l}\text { Após exposição a superfícies próximas } \\
\text { ao paciente }\end{array}$ & $51(87,9 \%)$ & $22(84,6 \%)$ & $73(86,9 \%)$ & 0,677 \\
\hline
\end{tabular}

* Fonte: Dados dos autores.

* Considerou-se significativo $p<0,05$.

\section{DISCUSSÃO}

Do total de participantes do estudo, 69\% pertencem à classe de enfermagem, e do sexo feminino. Em relação à faixa etária há prevalência de adultos jovens, pois encontramse na terceira e quarta década de vida.

Entre os profissionais médicos igualmente, predominou o sexo feminino, no entanto em uma faixa etária mais jovem, ou seja, em segunda e terceira década. Resultados semelhantes foram encontrados em estudo que pontua que no cenário atual há uma tendência à feminização da medicina no Brasil, pois 56,2\% são mulheres, com 29 anos ou menos (SCHEFFER et al., 2015).

Em relação ao tempo de atuação profissional na instituição preponderaram os que atuavam há mais de cinco anos o que indica baixa rotatividade. Destes, 86,9\% cumpriam jornada laboral de 40 horas, o que relaciona-se à maioria dos participantes integrarem unidades de ESF.

A prática de HM tem sido um desafio para a OMS que tem se preocupado com a melhoria da qualidade do cuidado prestado, visto que se trata de um direito do indivíduo e dever dos serviços de saúde. Segundo o Instituto de Medicina (IOM), dos Estados Unidos 
da América (EUA), a qualidade na assistência pode ser definida como o grau em que os serviços de saúde aumentam a possibilidade de obter resultados desejados com o nível de conhecimento científico atual (WHO, 2009). Neste sentido, destacam-se os treinamentos como ferramentas de atualização, nos serviços de saúde, com a finalidade de oferecer uma assistência qualificada e livre de danos.

Nessa perspectiva, o Ministério da Saúde (MS), enfatiza que os serviços tem a responsabilidade de ofertar ações educativas frequentes e periódicas sobre a $\mathrm{HM}$ a todos os profissionais de saúde, pautadas nos cinco momentos da HM e técnicas adequadas (BRASIL, 2009).

No que tange a receber treinamentos sobre a temática em estudo $60,4 \%$ dos participantes da enfermagem e $61,5 \%$ da classe médica responderam de forma afirmativa. Mesmo que a maioria afirma ter recebido treinamento, ainda um contingente de profissionais atuantes na assistência á saúde dizem que não receberam nenhum tipo de instrução, o que pode refletir em lacuna no conhecimento sobre o tema, bem como na adesão a esta prática.

Nesse sentido, estudo denota que ações educativas de caráter permanente constituem formas de oferecer conhecimento, proporcionar reflexão sobre o processo de trabalho e oportunizar crescimento profissional para construção do cuidado. Ainda o autor enfatiza dificuldades na operacionalização, devido à sobrecarga e capacitações insuficientes, que refletem no cuidado aos usuários (BOMFIM et al., 2017). Neste mesmo contexto, pesquisa que avaliou a adesão da $\mathrm{HM}$, em uma equipe multidisciplinar, concluiu que profissionais enfermeiros tiveram menos oportunidades de efetiva-la e relacionaram à sobrecarga administrativa (MOTA et. al 2014).

Segundo o MS, além dos treinamentos, o serviço de saúde deve dispor de infraestrutura adequada, com acesso imediato a pias com fornecimento contínuo de água, sabonete líquido, papel toalha, bem como preparações alcoólicas para a HM no ponto de assistência (BRASIL, 2013). Em relação a este aspecto, dados do presente estudo indicam que em ambas as categorias, a maioria dos profissionais reconhecem a existência de preparação alcoólica disponível na instituição.

Em relação ao conhecimento referente à rota de transmissão cruzada de infecção, um alto percentual da classe médica, $92,3 \%$ e de enfermagem $86,2 \%$ identificam as mãos como a principal via. Esse dado denota diferença sutil, entre as categorias profissionais, sem significância estatística. Estudo com profissionais do sistema sanitário público de Andalucía obteve resultados semelhantes ao evidenciar que 95,2\% dos participantes tem conhecimento adequado sobre a rota de transmissão (PÉREZ-PÉREZ P et al. 2015).

As infecções cruzadas são ocasionadas pela transmissão de microrganismos de um paciente a outro, por meio das mãos dos profissionais da área de saúde, acompanhantes e visitantes, pelo ar ou objetos contaminados (ALBUQUERQUE et al., 2013). Neste sentido, com a finalidade de prevenir infecção cruzada do paciente, os participantes da pesquisa demonstraram conhecimento ao afirmarem, $98,2 \%$ e $100 \%$, dos 
profissionais de enfermagem e médicos, respectivamente, que as mãos devem ser higienizadas antes de contato com o paciente e após contato com fluídos corporais. Após exposição a superfícies próximas ao paciente obteve-se um percentual afirmativo inferior, ou seja, $87,9 \%$ da enfermagem e $84,6 \%$ da médica, considerados satisfatórios.

Quanto ao conhecimento sobre o tempo mínimo necessário para a solução alcoólica destruir os microrganismos nas mãos dos profissionais, evidencia-se conhecimento insipiente, em ambas as classes, 36,2\% da enfermagem e 30,8\% da médica afirmaram ser de 20 segundos. Estudo que objetivou avaliar o conhecimento de profissionais de enfermagem, em relação a HM constatou que 36,3\% indicaram o tempo mínimo para solução alcoólica destruir microrganismo, conforme preconiza o MS, ou seja, 20 a 30 segundos (BRASIL, 2013; DERHUN et al. 2016).

Em relação à técnica de $\mathrm{HM}$, os participantes foram unanimes ao afirmar que a preparação alcoólica deve cobrir todas as superfícies das mãos, expresso em 96,5\% dos profissionais de enfermagem e $100 \%$ da classe médica. Dados semelhantes foram encontrados em pesquisa realizada com profissionais atuantes em uma unidade de pronto socorro de um hospital universitário, em que 100\% dos enfermeiros, 96\% dos técnicos de enfermagem e 96\% dos médicos responderam de forma correta (ZOTTELE, 2016).

Quanto à necessidade de as mãos estarem secas antes da fricção com preparação alcoólica, a maioria dos participantes responderam positivamente. Já acerca de secá-las com papel toalha após fricção, observou-se predomínio de acertos, uma vez que, afirmaram não secá-las, em ambas as classes, corroborando com achados de outro estudo (ZOTTELE, 2016).

Da mesma forma, no que tange aos os itens evitáveis, constata-se que a maioria dos participantes da equipe de enfermagem e a totalidade dos respondentes da classe médica concordam que não devem ser usadas joias e unhas postiças, no ambiente de trabalho. Resultado que vem ao encontro de recomendações do MS, na medida em que esses adornos representam um sítio de proliferação de microrganismos.

Referente ao creme para as mãos $41,3 \%$ dos profissionais de enfermagem e $34,6 \%$ dos médicos afirmam que deve ser evitado seu uso. Pesquisa com objetivo de avaliar 0 conhecimento de profissionais da saúde em relação a HM revela que eles não associaram essa prática à possiblidade de contaminação (SÁNCHEZ et al., 2014). Estudo infere que o uso frequente de preparações alcóolicas nas mãos pode causar ressecamento, no entanto, a adição de emolientes e umectantes pode minimizar este efeito, bem como sugere a adição de glicerol ou outro agente hidratante (CORDEIRO; LIMA, 2016). Ademais, o MS orienta, no manual técnico de HM, acerca do uso regular e individual de creme protetor para as mãos (BRASIL, 2013).

Destaca-se ainda, a importância do cuidado com as mãos, justificada pela capacidade da pele em armazenar microrganismos após interações com o meio ambiente, contato com superfícies, objetos e pessoas. Nesse sentido, participantes do estudo reconhecem, com elevado percentual, que maçaneta de portas tem potencial de contaminar 
as mãos e transmitir microrganismos aos pacientes se não higienizadas antes de tocá-los.

No que se refere à pele intacta do próprio paciente $68,9 \%$ dos participantes da classe de enfermagem e 65,4\% da classe médica responderam afirmativamente. Estudo afirma que a maioria das infecções humanas são causadas por bactérias que estão presentes na flora comensal do paciente e passam a causar processo patológico quando transmitidas para zonas desprotegidas, fora do seu habitat natural (BARATA, 2013). Ao considerar que todas as superfícies no serviço de saúde são contaminadas, o MS, no protocolo para prática de higiene das mãos nos serviços de saúde, preconiza que estas devem ser higienizadas após o contato com o paciente, bem como com superfícies deste ambiente (BRASIL, 2013).

Identifica-se que os profissionais participantes deste estudo, atuantes na atenção básica de saúde possuem conhecimento relativo referente à higienização das mãos. Quando relacionado o conhecimento entre categorias profissionais com o teste Quiquadrado de Pearson, mostrou em todas as variáveis do estudo, que não ocorreu diferença estatística. É possível verificar vulnerabilidade em alguns aspectos o que explicita a necessidade de ofertar atividades educativas permanentes no intuito de fortalecer o conhecimento sobre a importância da temática, bem como ampliar a percepção e compreensão sobre a mesma.

\section{CONSIDERAÇÕES FINAIS}

Resultados permitem afirmar que os profissionais demonstram conhecimento, no entanto lacunas são identificadas. Importante destacar que um percentual dos participantes do estudo, afirmaram não receber treinamentos sobre HM, o que denota fragilidades no conhecimento, em relação ao tempo mínimo para que a fricção com preparação alcoólica seja efetiva, itens evitáveis e superfícies com potencial para contaminação das mãos. Ao considerar que estes aspectos são relevantes na prevenção e/ou disseminação de infecções cruzadas, constata-se a indispensabilidade de ações educativas voltadas à conscientização, motivação e instrução dos profissionais sobre a temática.

Nesta perspectiva as ações de educação permanente devem ser implementadas na atenção básica por meio de espaços de discussões, atualizações sobre índices epidemiológicos, atividades práticas e dinâmicas em grupo, que despertem a responsabilização da equipe a buscar uma assistência qualificada e livre de danos.

É necessário que novos estudos, sejam realizados, na atenção básica, no intuito de confrontar o conhecimento com a efetivação da prática da HM, por meio de metodologias que permitem a observação da prática da HM dos profissionais. 


\section{REFERÊNCIAS}

ALBUQUERQUE, Adriana Montenegro de. et al. Infecção cruzada no Centro de Terapia Intensiva à luz da literatura. Rev. Ciência \& Saúde Nova Esperança, v. 11, n. 1, p. 7887, jun. 2013. Disponível em< http://www.facene.com.br/wpcontent/uploads/2010/11/INFEC\%E2\%94\%9C\%2587\%E2\%94\%9C\%25830-CRUZADANO-CENTRO-.pdf >. Acesso em: 16 nov. 2016.

ANVISA. Agência Nacional de Vigilância Sanitária. Organização Mundial de Saúde (OMS); Organização Pan-Americana da Saúde(OPAS). Guia para implementação: um guia para a implantação da estratégia multimodal da OMS para a melhoria da higienização das mãos. 2008. Disponível em<http://portal.anvisa.gov.br/wps/wcm/connect/71ac2f0047457>. Acesso em: 25 nov. 2016.

Barata, Joana Carolina. Infecções Associadas à Prestação de Cuidados de Saúde. 2013. 66 f. Tese (Mestrado Integrado em Ciências Farmacêuticas) Repositório Científico Lusófona. RECIL. Escola de Ciências e Tecnologia da Saúde ECTS, Lisboa (PT).

BOMFIM, Eliane dos Santos. et al. Educação permanente no cotidiano das equipes de saúde da família: utopia, intenção ou realidade? Rev Fund Care. v.2, n.9, p.526-535. 2017.

BRASIL. Ministério da Saúde. Agência Nacional de Vigilância Sanitária. Assistência Segura: Uma Reflexão Teórica Aplicada à Prática. Brasília: Ministério da Saúde, 2013. 168 p. Disponível em<http://www20.anvisa.gov.br/segurancadopaciente/images/documentos/livros/Livro1 Assistencia_Segura.pdfn>. Acesso em: 07 Out. 2016.

BRASIL. Ministério da Saúde. Agência Nacional de Vigilância Sanitária. Documento de referência para o Programa Nacional de Segurança do paciente. Brasília: Ministério da Saúde, 2014. 42 p. Disponível

em<http://faa.edu.br/portal/PDF/livros_eletronicos/enfermagem/doc_ref_prog_nac_seg.pdf >. Acesso em: 12 Out. 2016.

BRASIL. Ministério da Saúde. Agência Nacional de Vigilância Sanitária. Segurança do paciente em serviços de saúde: Higienização das mãos. Brasília: Ministério da Saúde, 2009. 105 p. Disponível

em<file:///D:/Meus\%20Documentos/Downloads/seguranca_paciente_servicos_saude_higi enizacao_maos_verde.pdf>. Acesso em: 15 Abr. 2018.

CORDEIRO, Valquíria de Britto; LIMA, Carlos Bezerra de. Higienização das mãos como ferramenta de prevenção e controle de infecção hospitalar. Temas em Saúde. v. v. 16, n. 2, p. 425-44. 2016. Disponível em<http://temasemsaude.com/wpcontent/uploads/2016/08/16224.pdf>. Acesso em: 20 Mar.2018.

DERHUN, Flávia Maria. et al. Conhecimento de profissionais de enfermagem sobre higienização das mãos. Cogitare Enferm. v. 21, n. 3, p. 01-08, Jul/set. 2016. Disponível em<http://revistas.ufpr.br/cogitare/article/view/45588/pdf>. Acesso em 17 nov. 2016.

LIMA, Francisco Daniel Motta. A Segurança do paciente e intervenções para a qualidade 
dos cuidados em saúde. Rev. Espaço para a Saúde, n.3, v.5, p. 22-29. 2014. Disponível em< file:///D:/Meus\%20Documentos/Downloads/18190-84575-2-PB\%20(2).pdf>. Acesso em: 27 Nov. 2016.

MOTA, Écila, Campos. et al. Higienização das mãos: uma avaliação da adesão e da prática dos profissionais de saúde no controle das infecções hospitalares. Revista de Epidemiologia e Controle de Infecção. v. 4, n. 1 p. 2-17. 2014. Disponível em<https://online.unisc.br/seer/index.php/epidemiologia/article/viewFile/4052/3379>. Acesso em: 02 dez. 2016.

PÉREZ-PÉREZ, Pastora. et al. Higiene de las manos: conocimientos de los profesionales y áreas de mejora. Caderno de Saúde Pública. v. 31, n. 1, p. 149-60. Jan, 2015. Disponível em: <http://www.scielo.br/pdf/csp/v31n1/0102-311X-csp-31-01-00149.pdf>. Acesso em: 17 nov. 2016.

SÁNCHEZ, José Luis Cobo. et al. Percepción y conocimientos de los profesionales sanitarios de una unidad de Nefrología sobre la higiene de manos: estudio comparativo.

Rev Enferm Nefrol, v.17, n.1, p.28-34. Enero-Marzo 2014. Disponível em<http://www.redalyc.org/pdf/3598/359833153005.pdf>. Acesso em: 18 nov. 2016.

SCHEFFER, Mário. et al. Demografia Médica no Brasil 2015. Departamento de Medicina Preventiva, Faculdade de Medicina da USP. Conselho Regional de Medicina do Estado de São Paulo. Conselho Federal de Medicina. São Paulo, 2015. 284 p. Disponível em< http://www.usp.br/agen/wp-content/uploads/DemografiaMedica30nov2015.pdf>. Acesso em 10 nov.2016.

SILVA, Francielle Maciel. et al. Higienização das mãos e a segurança do paciente pediátrico. Rev. Ciência y enfermaria, n. XIX, v. 2. 2013. Disponível em< http://www.scielo.cl/scielo.php?script=sci_arttext\&pid=S0717-95532013000200010 >. Acesso em: 26 Nov. 2016.

SOUZA, Francisco Edson de. et al. Segurança do paciente na atenção primária à saúde e a implementação de uma cultura de segurança. Mostra Interdisciplinar do curso de Enfermagem. Centro Universitário Católica de Quixadá. Unicatólica . v. 2, n. 2. 2016. Disponível em< http://publicacoesacademicas.fcrs.edu.br/index.php/mice/article/view/1166/939>. Acesso em: 20 Mar. 2018.

SOUZA, Lucas Melo de, et al. Adesão dos profissionais de terapia intensiva aos cinco momentos da higienização das mãos. Revista Gaúcha de Enfermagem. n. 4, v. 36, p. 21-8. dez 2015. Disponível em<http://www.seer.ufrgs.br/RevistaGauchadeEnfermagem/article/viewFile/49090/35654> . Acesso em: 25 nov. 2016.

WORLD HEALTH ORGANIZATION. WHO Guidelines on Hand Hygiene in Health Care. First Global Patient Safety Challenge. Clean Care is Safer Care. 2009. 270 p. Disponível em<http://www.who.int/gpsc/5may/back ground/5moments/en/> . Acesso em: 26 Out. 2016.

Zotelle, Caroline. Higienização das mãos: conhecimento e adesão de profissionais da saúde em unidade de pronto-socorro. 2016. 124 f. Dissertação (Mestrado do Programa de PósGraduação em Enfermagem - área de Concentração Cuidado, 
Educação e Trabalho em Enfermagem e Saúde) - Curso de Mestrado em Enfermagem. UFSM, Universidade Federal de Santa Maria, Santa Maria (RS). 